\title{
PEMBERIAN EDUKASI PENGELOLAAN SAMPAH BERBASIS MASYARAKAT DALAM RANGKA PENINGKATAN PENGETAHUAN MASYARAKAT DI DESA PEMURUS, KECAMATAN ALUH-ALUH, KABUPATEN BANJAR
}

\author{
Dian Rosadi1), Zulfa Emelda²), Elwan Mustawan³), Diny Febrianita'), I Dewa Ayu Yulia Adelina5) \\ 1)Departemen Epidemiologi, Program Studi Kesehatan Masyarakat, Fakultas Kedokteran, Universitas Lambung \\ Mangkurat, Banjarmasin, Kalimantan Selatan, Indonesia \\ ${ }^{2,5)}$ Program Studi Kesehatan Masyarakat Minat Administrasi dan Kebijakan Kesehatan, Fakultas Kedokteran, \\ Universitas Lambung Mangkurat, Banjarmasin, Kalimantan Selatan, Indonesia \\ ${ }^{3)}$ Program Studi Kesehatan Masyarakat Minat Epidemiologi, Fakultas Kedokteran, Universitas Lambung Mangkurat, \\ Banjarmasin, Kalimantan Selatan, Indonesia \\ 4)Program Studi Kesehatan Masyarakat Minat Keselamatan dan Kesehatan Kerja, Fakultas Kedokteran, Universitas \\ Lambung Mangkurat, Banjarmasin, Kalimantan Selatan, Indonesia \\ Corresponding author : Zulfa Emelda \\ E-mail : emeldazulfa@gmail.com
}

Diterima 23 Juni 2021, Direvisi 23 Juli 2021, Disetujui 24 Juli 2021

\begin{abstract}
ABSTRAK
Sampah adalah material sisa, yang diproduksi ke alam baik dalam bentuk padatan, cair, ataupun gas. Permasalahan sampah merupakan masalah yang besar di Desa Pemurus RT 001B dikarenakan cara pengelolaan sampah rumah tangga hanya dibuang ke sungai. Oleh karena itu diperlukan edukasi mengenai pengelolaan sampah. Pengelolaan sampah merupakan kegiatan yang sistematis, menyeluruh, dan berkesinambungan yang meliputi pengurangan dan penanganan sampah. Namun, karena Pandemi Covid-19 intervensi Pengalaman Belajar Lapangan (PBL) I dimodifikasi menjadi penyuluhan dengan menggunakan media poster, leaflet, booklet dan juga video edukasi mengenai upaya pengelolaan sampah yang dikirimkan langsung ke masyarakat. Kegiatan PBL II yang dilakukan secara daring menggunakan media aplikasi grup WhatsApp. Berdasarkan hasil pre-post test yang dilakukan dengan 14 peserta diketahui bahwa terdapat peningkatan dari hasil pre-test dengan hasil post-test. Berdasarkan pengetahuan masyarakat tentang pengolahan sampah terjadi peningkatan dengan nilai Sig $(0,004)>0,05$. Berdasarkan sikap masyarakat mengenai pengolahan sampah terjadi peningkatan dengan nilai Sig $(0,031)>0,05$. Diharapkan kepada masyarakat agar ikut berperan aktif untuk meningkatkan pengetahuan dan sikap mengenai pengelolaan sampah khususnya yang ada di Desa Pemurus RT 001B melalui penyuluhan sehingga nantinya dapat menciptakan derajat kesehatan yang lebih baik.
\end{abstract}

Kata kunci: pengelolaan sampah; desa pemurus rt 001b; penyuluhan.

\begin{abstract}
Waste is waste material, which is produced in nature in the form of solid, liquid, or gas. The waste problem is a big problem in Pemurus Village RT 001B because the way of managing household waste is only thrown into the river. Therefore, education about waste management is needed. Waste management is a systematic, comprehensive, and sustainable activity that includes waste reduction and handling. Due to the Covid-19, PBL I intervention was modified into outreach using posters, leaflets, booklets and educational videos about waste management efforts that were sent directly to the community. PBL II activities carried out online using WhatsApp group. Based on the results of the prepost test conducted with 14 participants, it was found that there was an increase from the pre-test results to the post-test results. Based on public knowledge about waste processing, there was an increase with the Sig value (0.004)>0.05. Based on people's attitudes regarding waste management, there was an increase with the value of $\mathrm{Sig}(0.031)>0.05$. It is hoped that the community will take an active role in increasing knowledge and attitudes regarding waste management, especially in Pemurus Village RT 001B through counseling so that later it can create better health degrees.
\end{abstract}

Keywords: waste management; pemurus village RT 001b; counseling.

PENDAHULUAN

Sampah merupakan sisa material yang

sudah tidak digunakan lagi setelah suatu proses. Sampah dapat dihasilkan oleh semua makhluk hidup baik dari manusia, hewan, maupun tumbuhan. Undang-Undang 
Pengelolaan Sampah Nomor 18 tahun 2008 menyatakan sampah adalah material sisa, yang diproduksi ke alam baik dalam bentuk padatan, cair, ataupun gas (Ariadi \& Tashid, 2018). Berdasarkan data Bank Dunia, jumlah sampah padat di dunia akan terus naik sebesar $70 \%$ tahun 2018 hingga tahun 2025, dari 1,3 miliar ton per tahun menjadi 2,2 miliar ton per tahun. Mayoritas kenaikan terjadi di negara berkembang. Di Indonesia, data Bank Dunia menyebutkan, produksi Sampah padat secara nasional mencapai 151.921 ton per hari. Hal ini berarti, setiap penduduk Indonesia membuang sampah padat rata-rata $0,85 \mathrm{~kg}$ per hari. Data yang sama juga menyebutkan, dari total sampah yang dihasilkan secara nasional, hanya $80 \%$ yang berhasil dikumpulkan, sisanya terbuang mencemari lingkungan (Nuryosuwito et al., 2018).

Pengelolaan sampah merupakan kegiatan yang sistematis, menyeluruh, dan berkesinambungan yang meliputi pengurangan dan penanganan sampah. Pengolahan sampah merupakan kegiatan yang dimaksud untuk mengurangi jumlah sampah, disamping memanfaatkan nilai yang masih terkandung dalam sampah itu sendiri (bahan daur ulang, produk lain dan energi). Pengolahan sampah dapat dilakukan berupa pengomposan, recycling/daur ulang, pembakaran (insinerasi), dan lain-lain (Samadikun, 2018). Menurut Kementerian Lingkungan Hidup dan Kehutanan Pengelolaan Sampah Nasional pada tahun 2017-2018, di Provinsi Kalimantan Selatan yang diproduksi perharinya mencapai 2.100 ton atau 766.000 ton setahun. Sementara untuk Kabupaten Banjar, jumlah sampah yang diproduksi perharinya sebanyak 113,90 ton/hari dengan jumlah sampah yang tidak terkelola sebanyak 45,16 ton/hari (Kementerian Lingkungan Hidup dan Kehutanan, 2018).

Identifikasi masalah yang didapatkan berdasarkan hasil diagnosa komunitas selama kegiatan Pengalaman Belajar Lapangan I (PBL I). Diagnosa komunitas dilakukan dengan pengumpulan data primer menggunakan kuesioner/survei kesehatan rumah tangga dan masyarakat untuk memperoleh permasalahan kesehatan yang terjadi di desa Pemurus RT 001B. Pengumpulan data sekunder yang didapatkan dari puskesmas Aluh-Aluh, Kepala Desa Pemurus, dan Bidan Desa Pemurus sebagai pendukung dari data primer, kemudian dijadikan sebagai hasil kegiatan diagnosa komunitas dan analisa situasi.

Berdasarkan hasil Musyawarah Tingkat Komunitas I (MTK I) yang dilakukan bersama Bagian Promosi Kesehatan Puskesmas, Ketua RT, dan perwakilan warga di RT 001B, terdapat 3 masalah yang perlu dilakukan penentuan prioritas masalah dan didiskusikan di Musyawarah Tingkat Komunitas (MTK), yaitu permasalaham sampah, merokok, dan hipertensi. Penentuan 3 masalah tersebut didapatkan dengan melihat tingkat keseriusan masalah, angka kesakitan, dan dampak dalam jangka panjang. Masalah-masalah tersebut perlu dilakukan penentuan prioritas masalah yang didiskusikan di MTK, karena hal ini berdampak terhadap kesehatan dan lingkungan di sekitar dengan menggunakan metode MCUA.

Penentuan skor pada MCUA didapatkan bahwa skor tertinggi adalah permasalahan pengelolaan sampah. Dari segi besarnya masalah, pengelolaan sampah dinilai sangat berat. Hal ini dikarenakan sebagian besar kepala keluarga berdasarkan hasil observasi lebih memilih mengelola sampahnya dengan cara dibakar atau dibuang ke sungai. Kegiatan membuang sampah kesungai atau membakar sampah sudah termasuk kegiatan yang sering dilakukan oleh masyarakat di Desa Pemurus RT 001B. Hal ini kemudian di perparah dengan tidak tersedianya tempat penampungan sampah sementara serta tidak adanya orang maupun instansi yang bertanggung jawab dalam mengelola sampah didesa tersebut.

Dikarenakan situasi pandemik saat ini, maka kegiatan intervensi yang akan dilkukan adalah kegiatan edukasi melalui Whatsapp Group. Masyarakat akan diberikan penyuluhan untuk meningkat kesadaran dan adanya perubahan perilaku agar lebih bijak dalam menangani masalah sampah. Penyuluhan dilakukan melalui Whatsapp Group dengan media poster, leaflet, booklet dan juga video edukasi mengenai upaya pengelolaan sampah dan pencegahan Covid-19 yang dikirimkan langsung ke masyarakat di Desa Pemurus RT 001B. Perlunya realisasi program tersebut sebagai intervensi terhadap permasalahan sampah yang ada di Desa Pemurus RT 001B agar tercapai tujuan akhir dari kegiatan ini.

\section{METODE}

Rancangan penelitian yang digunakan dalam penelitian ini adalah penelitian kualitatif deskriptif, yaitu suatu metode penelitian yang dilakukan dengan tujuan untuk menggambarkan tentang sesuatu keadaan secara objektif. Penelitian ini menggambarkan pengetahuan, sikap, dan perilaku masyarakat tentang pengelolaan sampah. Penelitian ini dilaksanakan secara daring melalui grup Whatsapp pada 16 November - 1 Desember 2020 dilakukannya intervensi sampai dengan penyuluhan. 
Populasi dari penelitian ini adalah masyarakat yang berada di Desa Pemurus RT 001B, Kecamatan Aluh-Aluh, Kabupaten Banjar. Sampel pada penelitian ini diampil dengan teknik Simple Random Sampling, yaitu pengambilan anggota sample dari populasi yang dilakukan secara acak tanpa memperhatikan strata yang ada dalam populasi itu. Sampel dalam penelitian ini adalah masyarakat Desa Pemurus RT 001B yang mengikuti kegiatan intervensi hingga penyuluhan melalui grup Whatsapp yang berjumlah 14 orang.

Instrumen yang digunakan adalah kuesioner pre dan post test yang berisi pertanyaan-pertanyaan yang berkaitan dengan pengelolaan sampah dan kepada masyarakat Desa Pemurus RT 001B melalui google form. Data yang diperoleh dari hasil kuesioner diolah dalam bentuk tabel dan dibandingkan dengan nilai standar pada masing-masing item untuk kemudian diambil kesimpulan secara obyektif.

$$
\text { Adapun beberapa tahapan }
$$

perencanaan kegiatan yang dilakukan pada Pengalaman Belajar Lapangan (PBL) II dapat dilihat pada gambar 1 , yaitu:

1. Mengumpulkan Kontak Masyarakat dan membuat grup WhatsApp

Sebelum dilakukannya kegiatan Pengalaman Belajar Lapangan (PBL) II ini, terlebih dari dari tim UP PBL beserta mahasiswa melakukan pengumpulan kontak masyarakat yang dijadikan sasaran dalam kegiatan intervensi. Kontak yang dikumpulkan disini adalah kontak yang terdaftar dalam WhatsApp karena kegiatan dilaksanakan via grup WhatsApp. Ketentuan jumlah minimal kontak masyarakat yang dimiliki sebanyak 15 kontak. Kelompok 10 sendiri tidak berhasil mendapatkan syarat kontak minimal, kontak masyarakat Desa Aluh-Aluh Besar RT. 03 yang dapat dikumpulkan sebanyak 14. Setelah mempunyai grup WhatsApp, kelompok melakukan rapat persiapan yang membahas terkait rangkaian kegiatan, metode kegiatan, dan media kegiatan yang akan dilakukan pada kegiatan intervensi Pengalaman Belajar Lapangan (PBL) II ini. Rapat persiapan dilakukan via online melalui grup WhatsApp kelompok 10.

2. Memberikan Penyuluhan

Setelah kelompok melakukan rapat persiapan, dilanjutkan dengan penyusunan dan pembuatan pre-post, materi, dan media yang digunakan dalam kegiatan intervensi Pengalaman Belajar Lapangan (PBL) II ini. Prepost test, kelompok 10 membuat soal pilihan ganda sebanyak 10 soal yang terbagi menjadi 5 soal tentang pengetahuan pengelolaan sampah, 5 soal tentang sikap pengelolaan sampah. Soal-soal pre-post dibuat berdasarkan materi yang akan disampaikan, yaitu terkait dengan pengelolaan sampah.

3. Pre-test dan post-test

Kegiatan pre-test dan post-test dilakukan untuk menilai pengetahuan yang dimiliki oleh masyarakat pada saat sebelum dan sesudah diberikannya materi penyuluhan tentang Pengelolaan Sampah. Adapun jumlah soal yang diberikan sebanyak 5 soal. Masyarakat menjawab soal menggunakan google form yang telah disediakan dan dibagikan melalui grup Whatsapp. Sebelum dibagikan, pre-test dan post-test yang telah dibuat terlebih dahulu di konsultasikan dengan dosen pembimbing.

Dalam kegiatan ini, masyarakat yang berpartisipasi dengan mengisi pre-test dan post-test sebanyak 14 orang.

4. Monitoring dan Evaluasi

Monitoring pada Pengalaman Belajar Lapangan (PBL) oleh Kelompok 10 yang dilaksanakan di Desa Pemurus RT 001B merupakan bagian dari evaluasi jangka panjang. Monitoring adalah suatu langkah untuk mengkaji kegiatan yang telah dilaksanakan sesuai dengan rencana, mengidentifikasi masalah yang muncul agar segera diatasi, serta menilai pola kerja dan manajemen yang digunakan sudah tepat untuk mencapai tujuan (Sani, 2013). Evaluasi pada intervensi ini dilihat berdasarkan hasil pre-test dan post-test yang telah diisi oleh masyarakat. Berdasarkan evaluasi tersebut menujukkan terjadinya peningkatan baik dari pengetahuan maupun sikap mengenai pengelolaan sampah setelah diberikan penyuluhan, hal ini menujukkan bahwa materi yang disampaikan dapat diterima dengan baik oleh masyarakat.

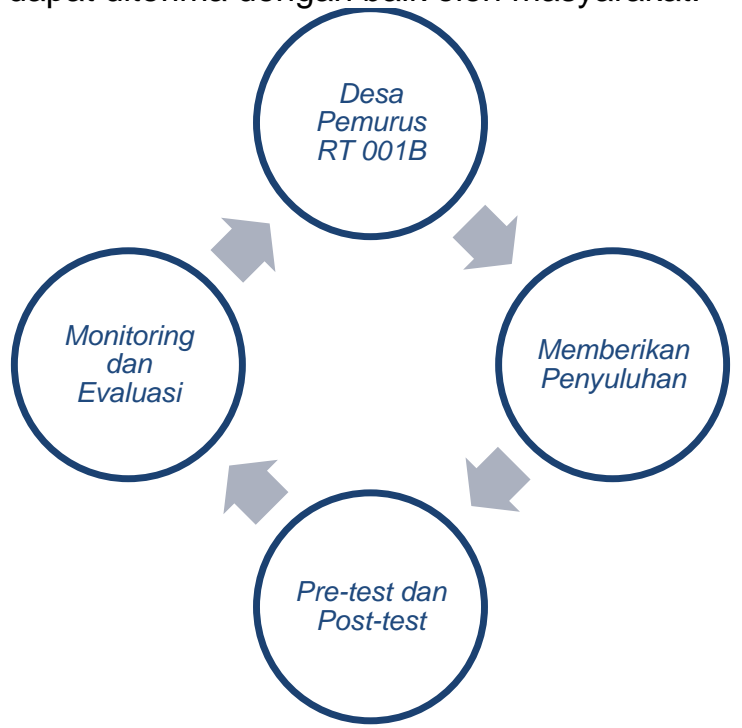

Gambar 1. Metode Perencanaan 
HASIL DAN PEMBAHASAN

\section{Pengetahuan Pengelolaan Sampah}

Tabel 1. Hasil Uji Normalitas Pre-test dan Post-test Penyuluhan Pengetahuan Pengelolaan Sampah di Desa Pemurus RT 001B.

\begin{tabular}{lllllll}
\hline & \multicolumn{3}{l}{$\begin{array}{l}\text { Kolmogorov- } \\
\text { Smirnov }\end{array}$} & \multicolumn{4}{c}{ Shapiro-Wilk } \\
\cline { 2 - 7 } & \multicolumn{3}{l}{ Statis } & \multicolumn{3}{c}{ Statis } \\
& tic & df & Sig. & tic & Df & Sig. \\
\hline Pre-Test & .242 & 14 & .026 & .853 & 14 & .025 \\
Post-Test & .502 & 14 & .000 & .438 & 14 & .000 \\
\hline
\end{tabular}

Uji normalitas merupakan salah satu cara untuk melihat sebaran data numerik berdistribusi normal atau tidak. Secara statistic uji normalitas dilakukan dengan uji Kolmogorov-Smirnov atau Shapiro Wilk. Uji Kolmogorov-Smirnov digunakan untuk sampel yang besar $(>50)$ sedangkan Uji Shapiro Wilk digunakan untuk sampel yang sedikit $(<50)$ (Dasman, 2020). Berdasarkan tabel 1 di atas diketahui bahwa nilai pre-test maupun post-test responden pada materi pengetahuan pengelolaan sampah berdistribusi tidak normal karena nilai signifikan yang kurang dari sama dengan 0,05 (Nilai Sig Pre-test pengetahuan pengelolaan sampah $=0,025<0,05$ dan Nilai Sig Post-test pengetahuan pengelolaan sampah= $0,0001<0,05)$. Apabila data tidak berdistribusi normal, maka selanjutnya akan dilakukan pengujian dilakukan dengan uji Wilcoxon untuk mengukur apakah adanya perubahan pengetahuan peserta kegiatan.

Berikut adalah tabel uji Wilcoxon untuk menilai apakah ada perbedaan pengetahuan antara sebelum dan setelah dilakukannya intervensi berupa penyuluhan:

Tabel 2. Hasil Uji Wilcoxon Pre-test dan Post-test Penyuluhan Pengetahuan Pengelolaan Sampah di Desa Pemurus RT 001B.

\begin{tabular}{llll}
\hline Pengujian & $\begin{array}{l}\text { p- } \\
\text { value }\end{array}$ & Keterangan & Kesimpulan \\
\hline Pre-test & 0.004 & Ho ditolak & $\begin{array}{l}\text { Terdapat } \\
\text { perbedaan }\end{array}$ \\
\hline
\end{tabular}

Uji Wilcoxon merupakan uji statistic dua sampel dependen non-parametrik yang dikembangkan oleh Wilcoxon (Ismail, 2018). Pada tabel 2 terlihat nilai Sig $(0,004)<0,05$ yaitu Ho ditolak yang artinya ada perbedaan yang signifikan antara pengetahuan masyarakat di Desa Pemurus RT 001B pada saat pengisian kuesioner sebelum (pre-test) dan sesudah (post-test) diberikan materi penyuluhan mengenai pengelolaan sampah.
Sikap Pengelolaan Sampah

Tabel 3. Hasil Uji Normalitas Pre-test dan Post-test Penyuluhan Sikap Pengelolaan Sampah di Desa Pemurus RT 001B.

\begin{tabular}{lllllll}
\hline \multicolumn{3}{c}{ Kolmogorov- $^{\text {Smirnov }}{ }^{\mathrm{a}}$} & \multicolumn{4}{c}{ Shapiro-Wilk } \\
\cline { 2 - 7 } & Statis & \multicolumn{3}{c}{ Statis } \\
& tic & df & Sig. & tic & Df & Sig. \\
\hline Pre-Test & .290 & 14 & .002 & .785 & 14 & .003 \\
Post-Test & .443 & 14 & .000 & .576 & 14 & .000 \\
\hline
\end{tabular}

Uji normalitas merupakan salah satu uji mendasar yang dilakukan sebelum melakukan analisis data lebih lanjut dan dijadikan landasan dalam uji statistic meskipun semua data tidak dituntut harus normal. Pada penelitian ini menggunakan Uji Shapiro Wilk dikarenakan sampel yang sedikit (<50) (Dasman, 2020). Berdasarkan tabel 3 di atas diketahui bahwa baik nilai pre-test maupun post-test responden pada materi sikap pengelolaan sampah berdistribusi tidak normal karena nilai signifikan yang kurang dari sama dengan 0,05 (Nilai Sig Pre-test sikap pengelolaan sampah = $0,003<0,05$ dan Nilai Sig Post-test sikap pengelolaan sampah $=0,0001<0,05)$. Dikarenakan data tidak berdistribusi normal, maka pengujian selanjurnya dilakukan dengan uji Wilcoxon.

Berikut adalah tabel uji Wilcoxon untuk menilai adanya perbedaan pengetahuan anatar sebelum dan setelah dilakukannya intervensi berupa penyuluhan:

Tabel 4. Hasil Uji Wilcoxon Pre-test dan Post-test Penyuluhan Sikap Pengelolaan Sampah di Desa Pemurus RT 001B.

\begin{tabular}{llll}
\hline Pengujian & $\begin{array}{l}\text { p- } \\
\text { value }\end{array}$ & Keterangan & Kesimpulan \\
\hline Pre-test & 0.031 & Ho ditolak & $\begin{array}{l}\text { Terdapat } \\
\text { perbedaan }\end{array}$ \\
Post-test & 0.02 & &
\end{tabular}

Uji Wilcoxon Signed Rank Test merupakan uji non-parametrik untuk mengukur signifikansi perbedaan antara dua kelompok data berpasangan berskala ordinal dan numeruk yang tidak berdistribusi normal (Endra, 2017). Pada tabel 4 terlihat nilai Sig $(0,031)<$ 0,05 yaitu Ho ditolak yang artinya ada perbedaan yang signifikan antara sikap masyarakat di Desa Pemurus RT 001B pada saat pengisian kuesioner sebelum dan sesudah diberikan materi penyuluhan mengenai pengelolaan sampah.

Pemberdayaan masyarakat yang merupakan salah satu kegiatan utama dalam $\mathrm{RHL}$ dilakukan dengan pendekatan peningkatan pengetahuan dan keterampilan melalui pelatihan, pendampingan, dan penyuluhan; pengembangan kesempatan usaha; pemberian akses legalitas (khususnya 
untuk kawasan hutan melalui Hutan Kemasyarakatan); pemberian insentif secara kelompok termasuk dalam bentuk pemberian bantuan; pengembangan kerja sama antar sektor; pengembangan akses pasar antara lain melalui kegiatan promosi, temu usaha, dan fasilitasi kerja sama kemitraan, serta pengembangan kemitraan antara kelompok tani dan mitra usaha (Indrawati, 2016).

Hasil dari kegiatan pembedayaan masyarakat dalam Pengalaman Belajar Lapangan (PBL) yang dilakukan di Desa Pemurus RT 001B, Kecamatan Aluh-aluh, Kabupaten Banjar berupa penyuluhan yang dilakukan secara daring (online) mengenai Pengelolaan Sampah, didapatkan bahwa terjadi peningkatan pengetahuan pada masyarakat Desa Pemurus RT 001B mengenai pengelolaan sampah dilihat dari hasil pre-post test serta sikap warga mengalami peningkatan dilihat dari pre-post test.

Informasi akan memberikan pengaruh pada pengetahuan seseorang. Meskipun seseorang memiliki pendidikan yang rendah tetapi jika mendapatkan informasi yang baik dari berbagai media (poster, leaflet, dan video edukasi), maka hal ini akan dapat meningkatkan pengetahuan. Hal ini didukung dengan penenlitian yang dilakukan Ramadhanti CA tahun 2019, yang menyatakan bahwa pemberian penyuluhan dengan menggunakan media akan meningkatkan pengetahuan ibu. Penyuluhan dengan media merupakan salah satu metode untuk mengingkatkan pengetahuan melalui tulisan, gambar, dan video mengenai suat materi (Ramadhanti et al., 2019).

Sikap merupakan respon seseorang terhadap stimulus atau objek tertentu. Adanya pengingkatan sikap responden sebelum dan sesudah diberikan penyuluhan dikarenakan respon warga yang positif. Hal ini sejalan dengan penelitian yang dilakukan Agustina NMV tahun 2019, yang menyatakan adanya peningkatan sikap siswa pada sebelum dan sesudah diberikan penyuluhan mengenai pengelolaan sampah yang dipengaruhi oleh pengetahuan yang telah meningkat sehingga siswa semakin baik pula dalam bersikap (Agustina \& Notes, 2019).

\section{SIMPULAN DAN SARAN}

Berdasarkan kegiatan intervensi yang telah dilakukan oleh kelompok yang dilakukan secara daring melalui WhatssApp yaitu penyuluhan terhadap materi pengelolaan sampah kepada masyarakat di Desa Pemurus RT 001B. Kegiatan tersebut menghasilkan output bahwa terjadi peningkatan pengetahuan pada masyarakat Desa Pemurus RT 001B mengenai pengelolaan sampah berdasarkan hasil pre-test dan post-test yang telah diisi masyarakat. Berdasarkan pengetahuan masyaratat tentang pengolahan sampah terjadi peningkatan dengan nilai Sig $(0,004)>0,05$. Berdasarkan sikap masyarakat mengenai pengolahan sampah terjadi peningkatan dengan nilai Sig $(0,031)>0,05$. Perlu dilakukan monitoring agar masyarakat desa tidak membuang sampah disungai dan dapat mengelola sampah sebagai bentuk kepedulian masyarakat terhadap kesehatan dan kebersihan lingkungan, serta bentuk pencegahan penyakit.

Diharapkan mahasiswa dapat memperdalam kembali kemampuan sebagai fasilitator dan meningkatkan kemampuan dalam bekomunikasi terutama komunikasi dengan masyarakat dalam menyampaikan promosi kesehatan. Masyarakat di RT 001B Desa Pemurus diharapkan ikut berperan aktif berpartisipasi dalam upaya kesehatan pribadi maupun umum khususnya terkait dengan pengelolaan sampah sehingga nantinya dapat menciptakan derajat kesehatan yang lebih baik. Dinas Kesehatan serta instasi kesehatan lainnya diharapkan dapat membuat kebijakan tentang pengelolaan dana desa dan berkomitmen bersama-sama untuk menyelesaikan dan memecahkan permasalahan terkait sampah.

\section{UCAPAN TERIMAKASIH}

Kegiatan pengalaman belajar lapangan ini tidak akan berlaksana dengan baik, tanpa adanya dukungan dari berbagai pihak di dalamnya, mulai dari pihak Universitas Lambung Mangkurat, Program Studi Kesehatan Masyarakat, Pemerintahan daerah Kabupaten Banjar, Aparat Desa Pemurus, dan masyarakat setempat. Untuk itu, kami dari tim pengalaman belajar lapangan menyucapkan terima kasih kepada pihak-pihak yang telah yang turut berpartisipasi dalam kegiatan ini.

\section{DAFTAR RUJUKAN}

Agustina, N. M. V., \& Notes, N. (2019). Promosi Kesehatan dengan Metode Ceramah dapat Meningkatkan Pengetahuan Sikap dan Perilaku Siswa Tentang Pengelolaan Sampah. Journal of Chemical Information and Modeling, 9(2), 179-188.

Ariadi, D., \& Tashid. (2018). Prototipe Sistem Pengukur Ketinggian Permukaan Sampah. JOISIE Journal Of Information System And Informatics Engineering, 2(1), 18-25. https://doi.org/https://doi.org/10.35145/joi sie.v2i1.243

Dasman, H. (2020). Tanya Jawab Analisis Data: Prinsip Dasar dan Langkah- 
Langkah Aplikasi Praktis Pada Penelitian Kesehatan. Guepiedia.

Endra, F. (2017). Pedoman Metodologi Penelitian (Statistika Praktis). Sidoarjo: Zifatama Jawara.

Indrawati, D. R. (2016). Pemberdayaan Masyarakat Dalam Pengelolaan Das Mikro: Konsep Dan Implementasi. Kawistara - Jurnal Ilmiah Sosial Dan Humaniora, 6(2), 175-187. https://doi.org/10.22146/kawistara.15583

Ismail, H. F. (2018). Statistika untuk penelitian pendidikan dan ilmu-ilmu sosial. Kencana.

Kementerian Lingkungan Hidup dan Kehutanan. (2018). Sistem Informasi Pengelolaan Sampah Nasional. Https://Sipsn.Menlhk.Go.Id/Sipsn/.

Nuryosuwito, N., Soeparman, S., Wijayanti, W., \& Sasongko, M. (2018). Pengaruh Campuran Sampah Plastik dengan Katalis Alam terhadap Hasil Produk Pyrolisis. Jurnal Rekayasa Mesin, 9(2), 85-91.

https://doi.org/10.21776/ub.jrm.2018.009. 02.3

Ramadhanti, C. A., Adespin, D. A., \& Julianti, H. P. (2019). Perbandingan Penggunaan Metode Penyuluhan Dengan Dan Tanpa Media Leaflet Terhadap Pengetahuan Dan Sikap Ibu Tentang Tumbuh Kembang Balita. Diponegoro Medical Journal (Jurnal Kedokteran Diponegoro), 8(1), 99-120.

https://doi.org/https://doi.org/10.14710/d mj.v8i1.23304

Samadikun, B. P. (2018). Pengaruh Pendampingan Masyarakat dalam Pemilahan Sampah di Desa Pucung Kecamatan Tirto Kabupaten Pekalongan. Jurnal Presipitasi : Media Komunikasi Dan Pengembangan Teknik Lingkungan, 15(1), 46-52.

https://doi.org/10.14710/presipitasi.v15i1. 46-52

Sani, R. A. (2013). Inovasi Pembelajaran. Jakarta: PT. Bumi Aksara. 